\title{
“DOIS PESOS, DUAS MEDIDAS": JUSTIÇA, IMPARCIALIDADE E EQUIDADE NA MÍDIA FRANCESA CONTEMPORÂNEA
}

\author{
Roselyne Koren ${ }^{\mathrm{i}}$
}

Resumo: A igualdade de direitos, a imparcialidade e a equidade desempenham um papel primordial nos debates públicos do nosso tempo. De fato, nossos contemporâneos não cessam de levantar a questão da discriminação e da concorrência de vítimas. É então a transgressão da "regra de justiça" que permite perceber a natureza e as expectativas de tais questões. Em um primeiro momento, tentaremos propor uma síntese crítica das análises da regra da justiça propostas por Perelman em cinco de suas principais obras e, em seguida, submeteremos à prova a aplicação da regra usando extratos do discurso midiático que a invocam na apresentação de polêmicas e/ou de crises políticas ou sociais contemporâneas. Veremos, então, que a regra de justiça se situa no cruzamento entre raciocínios formais, próximos de uma razão teórica “imutável e eterna", e de uma "razão histórica”, da qual é igualmente, segundo Perelman (1989: 364), um "princípio constitutivo". Apresentaremos também casos paradoxais em que a aplicação da regra é considerada indesejável em nome de um sentimento de injustiça. Tentaremos então deduzir, a partir dessas análises, quatro verdades retóricas essenciais: a suspensão do ato de julgar não é uma garantia de equidade absoluta; o argumento precedente não deve sua força persuasiva ao respeito a uma verdade abstrata universal, mas a uma "razão histórica" prática; a importância ética fundamental da relação com o Outro na argumentação; o fato paradoxal de que os grandes princípios racionais constituem, muitas vezes, um obstáculo à justiça política e social.

Palavras-chave: Regra de Justiça. Imparcialidade. Equidade. Juízo de valor.

\begin{abstract}
Equal rights, impartiality and fairness play a central role in public debates today. Questions of discrimination and competition between victims are then at stake. The ins and outs of the rule of justice are thus perceived through its transgression. This paper will first propose a critical synthesis of the definition of this rule in five major works of Chaïm Perelman. It will then apply this theoretical frame to the analysis of media polemics and presentations of political or social crises. This type of application will show that the rule is situated at the crossroads between the theoretical formal conception of an "invariable and eternal reason" and a "historical reason" which is also one of his "constitutive principles" (Perelman 1989: 364). We will however also explore paradoxical cases where the application of the rule is considered as undesirable because it appears to the speaker as iniquitous. So we intend to deduce from a set of different and even opposed case studies the four following rhetorical truths: the act of renouncing to take a stand does not automatically warrant absolute equity, the persuasive strength of the argument of the "precedent" is not anchored in an abstract universal truth, but in a practical "historical reason", the ethical fundamental importance of the Other in argumentation, the paradoxical fact that grand rational principles can sometimes be an obstacle to political and social justice.
\end{abstract}

Keywords: Rule of justice. Impartiality. Equity. Value judgment.

i Docente da Universidade de Bar-llan, Israel. Coordenadora do grupo de pesquisa ADARR Analyse du Discours, Argumentation et Rhétorique. 
EID\&A - Revista Eletrônica de Estudos Integrados em Discurso e Argumentação, Ilhéus, n. esp. ADARR, mai.2016.

Os critérios e os valores que servem para justificar as regras de ação não podem estar isentos de críticas. [...] Aqueles que aspiram a mais justiça nas relações humanas devem estar preparados para considerar todas as acusações de parcialidade (PERELMAN, Ethique et Droit, 1990, p. 246).

\section{Introdução}

A igualdade de direitos, a imparcialidade e a equidade desempenham um papel primordial nos debates públicos do nosso tempo. De fato, nossos contemporâneos não cessam de levantar a questão da discriminação e da concorrência de vítimas, eles denunciam tomadas de posições partidárias às quais se aplicam frequentemente fórmulas como "dois pesos, duas medidas", "X com geometria variável”, balanço de vítimas "assimétrico" ou "indignação seletiva". Estas são transgressões da "regra de justiça" que permitem perceber a natureza e as expectativas de tais questões.

Esses três valores - igualdade, imparcialidade e equidade - estão intimamente ligados à operacionalização do argumento que a Nova Retórica, de Perelman, chama de "quase-lógico" por causa de sua semelhança com o raciocínio formal more geometrico. Por outro lado, esta regra deve seu prestígio a uma das consequências éticas de sua aplicação: a implementação de um "racionalismo igualitário" (PERELMAN, 1989, p. 202), reivindicando que as situações, ações, causas ou destinos idênticos sejam tratados, devido a esta identidade, da mesma maneira.

Num primeiro momento, tentaremos propor uma síntese crítica das análises da regra da justiça propostas por Perelman em cinco de suas obras: Le champ de l'argumentation (1970), L'Empire Rhétorique (1977), Le Traité de l'argumentation (1983), Rhétoriques (1989), Éthique et Droit (1990) ${ }^{1}$ e, em seguida, colocaremos à prova a aplicação da regra em extratos de discursos midiáticos ou midiatizados que a invocam na apresentação de polêmicas e/ou de crises políticas ou sociais contemporâneas.

A heterogeneidade de temas ou práticas discursivas em que a regra é invocada, explícita ou implicitamente - a saber: a apologia à imparcialidade do Estado, o balanço de vítimas "assimétrico", a assimilação e a nomeação por amálgama justificando o tratamento idêntico de duas entidades, a oscilação entre "blasfêmia" e "ofensa" racial" -, nos permitirá explorar os meandros da regra em diferentes contextos sócio-históricos. A regra de justiça se situa, de 
EID\&A - Revista Eletrônica de Estudos Integrados em Discurso e Argumentação, Ilhéus, n. esp. ADARR, mai.2016.

fato, no cruzamento entre os raciocínios formais, próximos de uma razão teórica "invariável e eterna" e de uma "razão histórica" da qual ela é igualmente, segundo Perelman (1989, p. 364), um "princípio constitutivo". Esse argumento é um topos ao qual cada locutor pode recorrer no quadro de diferentes práticas ou gêneros discursivos, desde que ele deseje implantar um ethos racional e imparcial ou solicitar a aplicação da regra a seu favor. No entanto, ao longo do caminho, encontraremos casos paradoxais em que a aplicação da regra é considerada indesejável, apesar de seu alto grau de imparcialidade e de justiça formal, em nome de um sentimento de equidade. Finalmente, analisaremos brevemente na conclusão, a relação entre a regra e a ética do jornalista.

O corpus constituído para esta finalidade compreende cinquenta artigos extraídos de jornais diários da imprensa nacional francesa (Libération, Le Monde e Le Figaro), de semanários (Le Nouvel observateur e L'Express), de mídias de circulação mensal (Le Monde diplomatique e Le Magazine littéraire), assim como de meios online (Mediapart, La Gazette d'arrêt sur image, Rue89), de blogs independentes ou que integram a edição online de Le Monde Diplomatique ou de diários nacionais, de sites como o INA ${ }^{2}$ - Instituto Nacional de Audiovisual -, ou o CRASH ${ }^{3}$ - Centro de Reflexão sobre a Ação e os Saberes Humanitários - Fundação Médicos Sem Fronteiras. Estes artigos foram publicados entre 1995 e 2015.

\section{Os meandros da "regra de justiça" na Nova Retórica}

A definição de "regra de justiça" proposta pela Nova Retórica (doravante NR) tem influências de filósofos como Leibniz (a "regra de seres idênticos"), Kant, Frege e Rawls, sem, entretanto, decidir-se por adotá-las. Perelman se distancia de tais influências em função do caráter formal e absoluto dos fundamentos universais das reflexões de tais filósofos. Apesar de sua fertilidade, essas teorias não possibilitam, em sua opinião, pensar ou tentar resolver os conflitos ancorados em realidades sócio-históricas específicas ${ }^{4}$. Essas abordagens muito formais obrigam os indivíduos a "oscilar

2 Institut National d'Audiovisuel - www.ina.fr

3 Centre de Réflexion sur l'Action et les Savoirs Humanitaires - Fondations Médecins Sans Frontières - www.msf-crash.org, www.raisonrepubliqueresistance.blogspirit.com.

4 Cf. Ibidem "Se atribuímos estado de valores universais como a verdade, justiça, beleza, que cada um evoca e ninguém recusa, é porque este acordo existe há tanto tempo e já faz parte das generalidades. Assim que se atreve a passar este acordo, in abstracto, aos casos de aplicação concreta, as controvérsias surgem imediatamente". É possível chegar ao acordo sobre a 
EID\&A - Revista Eletrônica de Estudos Integrados em Discurso e Argumentação, Ilhéus, n. esp. ADARR, mai.2016.

constantemente entre uma concepção realista, objetiva e dogmática e concepção nominalista, subjetiva e arbitrária” (ED, p. 180). Trata-se, portanto, para o retórico, de traçar uma via de cruzamento entre a versão formal essencialista da regra e de sua operacionalização no contexto de outro regime de racionalidade, aquele da razão prática. Isso, segundo ele, é a única chance que os "seres" têm para racionalizar a sua posição axiológica e evitar a armadilha de decisões arbitrárias ou relativistas em matéria de justiça.

A NR situa a implementação dessas decisões na trama das interações verbais entre um sujeito que justifica suas escolhas e um interlocutor que critica, julga e avalia seu comportamento para validá-lo ou se dissociar dele. E se há um dilema e não há consenso, pode-se recorrer, como nos tribunais que servem de modelo para a NR, a um terceiro imparcial, mas solidário, a quem confiaremos a função de julgar e a responsabilidade de decidir (TA, p. 78-83). Esse terceiro deve ser capaz de suspender, inicialmente, qualquer ato de julgamento e convocar, simultaneamente, como pode ser lido em rue $89^{5}$, os "políticos" a "reverem seu vocabulário para não dar a impressão de praticar dois pesos, duas medidas", o Estado a "se questionar, em vez de bradar por mais vigilância e por mais leis", os judeus a "aprenderem a criticar Israel quando ele está errado" e os muçulmanos a "entenderem que o Islã é fundamentalmente um estado de espírito aberto e tolerante".

A definição do argumento é a seguinte: "A regra de justiça exige a aplicação de um tratamento idêntico aos seres ou situações que integram uma mesma categoria" (TA, p. 294). O homem que quer ser "justo" e racional resistirá a seus "impulsos", "interesses" e "paixões", assim como a "suas tendências de compaixão e simpatia" (ED, p. 108), a fim de tratar da mesma forma os seres julgados idênticos, como iguais e permutáveis: "Tudo o que é dito de um" "deve também ser do Outro" - "Estas duas declarações são equivalentes e, portanto, têm o mesmo valor de verdade" (Ibidem, p. 109; CHA, p. 294).

Isso também explica a função primordial do argumento "estático" do

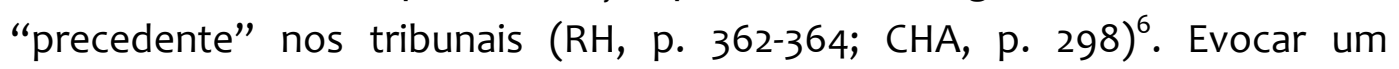
precedente é "assimilar um caso novo a um antigo", já julgado e validado,

necessidade de respeitar a regra de justiça, mas persiste o desacordo sobre as modalidades concretas de agir.

5 Al-Hakkak, no Rue89, 14/01/2015.

6 Cf., também, a noção de "precedente": CHA, p.296, 298, 302; ER, p.81; TA, p. 616; ED, p.111, 115, 119, 135-136, 243. 
EID\&A - Revista Eletrônica de Estudos Integrados em Discurso e Argumentação, Ilhéus, n. esp. ADARR, mai.2016.

devidamente ancorado na memória coletiva, aumentando assim suas chances de conseguir a adesão do auditório, evocando um passado e tradições comuns. Há mais de uma ligação entre a função do precedente e a referência epistemológica a um saber comprovado, dizem Perelman e Olbrechts-Tyteca (TA, p. 616). A regra de justiça pode até mesmo interferir de fato na "apreciação da força dos argumentos". Um saber em construção terá a mesma validade que seu "precedente", já que "o que pôde, em uma determinada situação, convencer, parecerá persuasivo em uma situação semelhante ou análoga. A aproximação entre situações será objeto, em cada disciplina particular, de análise e refinamento constante"7. O raciocínio que consiste em evocar um exemplo histórico conhecido por todos ou uma demonstração científica anterior, já aceita e validada, aumenta a força persuasiva de qualquer argumento que procura provar sua coerência interna: a referência a um saber admitido permite também que o pesquisador submeta seu atual objeto a um tratamento similar.

Mal tais definições tinham sido enunciadas e Perelman as problematiza no que concerne ao caráter formal. A regra, que testemunha a virtude do "sábio" (Ibidem, p. 108), parece-lhe, entretanto, inaplicável na maioria dos casos. De fato, o princípio seria admitido tão facilmente que talvez ele não pudesse nunca ser aplicado. (ER, p. 80): esse status se deve a um alto grau de generalidade e abstração sem controle das crises de conflitos sócio-históricos e casos de "opiniões humanas" ( $\mathrm{RH}, \mathrm{p}$.434). A imprecisão semântica de "idêntico" e a essencialização do ponto de vista a tornariam inaplicável. A regra "não nos diz quando os seres são essencialmente similares nem como eles devem ser tratados" (1990, p.111). Assim, é impossível aplicá-la sem ter respostas para estas perguntas. Invocá-la é, no entanto, muito benéfico para a avaliação do ethos do argumentador e sua conduta: a regra apresenta, diz Perelman e Olbrechts-Tyteca (1983, p. 296), "um aspecto de racionalidade inegável. Quando se relata a coerência de uma conduta, faz-se alusão quase sempre ao respeito à regra de justiça".

O que faz a força desta regra, por mais formal que ela seja, são os laços estreitos que a ligam a "uma concepção de ideal humano, individual e social", concepção em função da qual as instituições elaboram e justificam suas

7 Podemos ver nesse trecho de um editorial do Libération (06/07/2015), intitulado "Précédent", a confirmação da força desse argumento: "As cabeças duras das finanças se agarram a seus dogmas, como os Talibãs ao terno e gravata. Eles temem instaurar um precedente perigoso e empurram o Grexit". A solução que mantém a Grécia, apesar de suas dívidas, na zona do euro, arriscaria possibilitar que outros países peçam um tratamento idêntico. 
EID\&A - Revista Eletrônica de Estudos Integrados em Discurso e Argumentação, Ilhéus, n. esp. ADARR, mai.2016.

"regulamentações" (ED, p. 116). A elaboração de todo código penal inspira-se neste fato quando se trata, por exemplo, de "estabelecer uma proporcionalidade entre a gravidade dos delitos e a duração das penas", "entre os méritos e recompensas", "entre as necessidades e sua satisfação" (Ibidem). A formulação de um "ideal do homem e da sociedade" constitui aqui a condição de possibilidade de um acordo sobre a definição da natureza da justiça, acordo que permite evitar a armadilha de se recorrer à violência ${ }^{8}$. Este ideal deve, em princípio, corresponder às expectativas de um "auditório universal" constituído por um conjunto de "todos os seres de razão". Entretanto, mal estas declarações de princípio haviam sido enunciadas, Perelman (Ibidem) as reconfigura pelo prisma da noção de razão prática. Apenas uma interação argumentada entre "o racional" e "o razoável", entre os grandes princípios formais e as opiniões humanas, entre o conceito abstrato de auditório universal e suas muitas interpretações concretas particulares, poderão permitir a aplicação do princípio formal de justiça à vida política e social.

A NR tem, portanto, a finalidade de definir e de justificar um regime de racionalidade no qual razão teórica e razão prática "histórica" (RH, p. 364) não estão mais dissociadas. É no quadro das práticas discursivas que ocorre a transição entre essas duas concepções de racional. Se nenhum defensor da razão teórica não pode, diz Perelman, considerar que existe uma razão prática ou pensar na compatibilidade da demonstração e da argumentação, a abordagem oposta - passar da razão prática para a razão teórica demonstra a necessidade e a possibilidade de sua complementaridade na determinação do que é justo - parece perfeitamente viável para o autor de Ética e Direito: "A regra de justiça fornece a parte comum e puramente formal da atividade racional" (PERELMAN, 1990, p. 126). "Mas o conteúdo a que esta regra se aplica [...] é uma questão de opiniões humanas, opiniões essas que caracterizam a personalidade de seu autor e, por isso, todo o seu passado, toda a sua formação, toda a tradição que se estende e que, se necessário, aperfeiçoa e renova" (RH, p. 434).

Uma de suas variantes, "o argumento da reciprocidade", ilustra esta convicção de maneira particularmente significativa. A sua implementação envolve o entrelaçamento de um raciocínio formal e de considerações práticas, "fundadas na natureza das coisas" (RH, p. 298). A noção prática de

8 Cf. sobre a oposição entre retórica vs violência, CHA, p. 301, 304. 
EID\&A - Revista Eletrônica de Estudos Integrados em Discurso e Argumentação, Ilhéus, n. esp. ADARR, mai.2016.

"reciprocidade" tem o princípio de "simetria" como condição de possibilidade (ER, p. 83). Isto implica, em lógica formal, que se "os termos a e b, antecedente e consequente de uma relação R" (ER, p. 82), podem ser invertidos para que ab seja totalmente comparável a $b a$, os dois tipos de relação podem ser tratados exatamente da mesma forma. Aplicar este princípio a situações sócio-históricas concretas é salientar que duas situações distintas são, contudo, o "fiel da balança entre uma e outra" (TA, p. 297) e que é legítimo aplicar-lhes o mesmo tratamento. Assim, consideraremos "aprender" e "ensinar" como noções "simétricas" porque "aquilo que é honroso de aprender é honroso também de se ensinar" (Quintiliano citado por Perelman e Olbrechts-Tyteca, TA, p. 298). Aquilo que é uma ofensa para uns - a "mendicância" - deveria poder ser reavaliada pelo prisma de sua "contrapartida virtuosa" - "a caridade", protesta um mendigo (ER, p. 83). A Federação Internacional dos Direitos Humanos denuncia em uma carta aberta à União Europeia (UE), publicada, em 30 de julho de 2014, no Mediapart, a utilização indevida por parte da UE do argumento da reciprocidade e do "fiel da balança". Ela condena "os ataques de foguetes indiscriminados contra Israel pelo Hamas", ataques qualificados como "criminosos e injustificáveis", mas justificados pelo "direito legítimo de Israel de se defender dos ataques" seguindo a lógica do par nocional ofensivo/defensivo - "sem questionar a natureza dos crimes" humanitários cometidos por Israel. O Estado teria sido apenas convocado para garantir que suas respostas fossem "proporcionais e em conformidade com o direito internacional humanitário". A União Europeia, por conseguinte, foi ao mesmo tempo criticada e elogiada por Mediapart. O site a acusa de iniquidade por causa de uma aplicação excessivamente formal da variante do "fiel da balança", porque Israel, apesar de ter o direito de se defender, não teria dado a ordem relativa à violência das respostas. $\mathrm{O}$ Estado teria recorrido à violência desproporcional e a solicitação elogiável da UE teria sido perfeitamente inútil.

$\mathrm{O}$ argumento de reciprocidade pode mesmo constituir a condição de possibilidade de outro procedimento de racionalização de opinião: a autocrítica ou a reflexividade do ato de julgar. Uma obra utópica, como As Cartas Persas, de Montesquieu, pode muito bem "nos fazer pensar", reciprocamente, afirma Perelman (ER, p. 83), sobre "a estranheza dos nossos

9 A controvérsia em torno das noções de proporção e desproporção cumprem, como veremos mais à frente nos casos de balanço de vítimas, um papel importante nos debates e polêmicas em torno da aplicação de um mesmo tratamento aos dois campos de um conflito. 
EID\&A - Revista Eletrônica de Estudos Integrados em Discurso e Argumentação, Ilhéus, n. esp. ADARR, mai.2016.

próprios costumes" e levar-nos a nomear da mesma forma o que nos aparece idêntico. Este é o raciocínio do jornalista Laurent Joffrin, diretor do Libération, em um editorial publicado em 7 de junho de 2010:

Quantos artigos na imprensa democrática sobre Guantánamo, quantos sobre os métodos policiais em vigor nos regimes islâmicos? Efetivamente, existem dois pesos e duas medidas. Mas esse desequilíbrio mostra que a opinião democrática acredita em seus princípios e quer aplicá-los, em primeiro lugar, para si mesma. Espera-se mais de uma democracia do que de uma ditadura (JOFFRIN, In. Libération, 7/06/2010).

A decisão paradoxal de aplicar voluntariamente o princípio "dois pesos, duas medidas" resulta aqui da seguinte tomada de posição: uma democracia não pode resolver colocar um regime totalitário e seu contrário no mesmo plano, ela deve articular ação e ética por convicção. O fato de que a imprensa, instituição eminentemente democrática, mostra-se mais exigente em relação às democracias que em relação aos regimes ditatoriais seria uma forma de autocrítica perfeitamente legítima e racional.

A conceituação do regime de racionalidade da razão prática implica, então, que o retórico reconfigure a noção de identidade e que ele justifique a hipótese de que ela não pode ser absoluta. Só pode se tratar de uma identidade parcial à qual o sujeito da argumentação decidiu dar primazia. A reformulação da regra formal, portanto, leva às seguintes perguntas: "como tratar, de forma justa, seres que não são idênticos" ou ainda "seres considerados como essencialmente similares" (ED, p. 127-128; CHA, p. 295-296)? Assim, é o locutor que deve assumir a responsabilidade pela distinção entre diferenças insignificantes e semelhanças essenciais em função da finalidade que tem no contexto social e histórico no qual deve agir (ER, p. 80-81). É sua responsabilidade tomar uma série de decisões complexas que justificam a identificação pontual de seres que ele deseja tratar da mesma forma, apesar de suas diferenças (ED, p. 110).

Dessas "opiniões humanas" intrinsecamente discutíveis e refutáveis dependerá o desencadeamento de polêmicas em torno de duas críticas fundamentais: a acusação de discriminação e de não consideração das diferenças essenciais, arriscando arruinar um dos termos indevidamente sujeitos a um julgamento da equivalência (ER, p. 81-82; ED, p. 110).

A distinção entre a racionalidade formal e racionalidade prática conduz, enfim, Perelman a reajustar a qualificação formal da "regra de justiça" e a substituir a noção de "regra justa". O princípio formal não lhe parece aplicável 
EID\&A - Revista Eletrônica de Estudos Integrados em Discurso e Argumentação, Ilhéus, n. esp. ADARR, mai.2016.

ao mundo de "opiniões humanas" porque não é possível "esgotar", devido à sua abstração e à generalidade, "todo o conteúdo da ideia de justiça" (ED, p. 203-204), nem pensar a sua complexidade. Os critérios racionais permitem distinguir as "regras justas" daquelas que não o seriam e tais critérios são elaborados por meio de procedimentos argumentativos: "racionalizar", entendido não apenas como "verificar e demonstrar", "descobrir a verdade ou o erro", mas como "deliberar, criticar e justificar" (ED, p. 224) ${ }^{10}$. A necessidade de tais atos é ditada pelo fato de que se passa do domínio das evidências e da verdade referencial ao domínio da "decisão", da "ação" e da "escolha" (Ibidem). O argumentador aceita a priori o fato de que seus posicionamentos devem ser justificados porque eles são, em sua maior parte, intrinsecamente criticáveis e refutáveis. A crítica, outra condição de possibilidade fundamental deste regime de racionalidade, é o modo de ação do auditório que é chamado para julgar a conduta do proponente pelo prisma da "moralidade, legalidade [...], utilidade ou oportunidade de um comportamento, de uma decisão, de uma ação tomada ou proposta" (ED, p. 225). O que racionaliza essa concepção da crítica são os "critérios", "valores" e "normas" "previamente reconhecidos por aqueles que devem julgar a pertinência da crítica, dos méritos da refutação" (op. cit., p. 241).

Em resumo, uma "regra justa" é, no campo da razão prática, uma regra justificada, concernente à semelhança entre dois seres ou duas situações, apresentada como essencial, apesar das diferenças conhecidas e comprovadas, mas consideradas secundárias ou negligenciáveis, regra sujeita à crítica avaliativa do auditório e tida definitivamente como racional por sua adesão. O auditório certamente pode recusar seu acordo e, assim, comprometer a atribuição da qualificação de comportamento "justo". Isso pode acontecer especialmente quando uma aplicação muito formal, essencializante, da regra desperta nele, paradoxalmente, um sentimento de injustiça e de "revolta da consciência" (ED, p. 140, 171-172; CHA, p. 306), como veremos mais à frente no caso de balanços assimétricos de vítimas. Então, a imparcialidade, que é considerada inadequada e inaceitável, faz com que o locutor "corrija" e convoque outro valor: a equidade". De fato, o sentimento

10 Cf., sobre esta distinção, CHA, p. 292, 294, 301.

11 Cf. esta definição de Aristóteles, que ganhou destaque com Ricoeur (1995) no Prefácio do volume: "O equitativo, estando justo, não é justo segundo a lei, mas um corretivo da justiça legal. A razão é que a lei é sempre algo geral e existem casos de espécie pelas quais não é possível colocar uma declaração geral que se aplica com certeza ... Assim, é claro o que é justo, que o equitativo é justo e ele é superior a certos tipos de justo". Ética a Nicômaco, V, 15 (trad. J. Tricot). 
EID\&A - Revista Eletrônica de Estudos Integrados em Discurso e Argumentação, Ilhéus, n. esp. ADARR, mai.2016.

de injustiça e de se estar diante do absurdo pode resultar, no campo das opiniões, em um excesso de rigor na aplicação da versão formal e demasiado "estática" da "regra de justiça" (Ibidem, p. 198). Esta é a tese defendida por Laurent Joffrin na sequência do editorial citado acima:

Espera-se mais de uma democracia do que uma ditadura; rebater estas críticas em nome do realismo ou de uma equidade de aparência é minar os fundamentos morais e políticos dos regimes de liberdade. Assim, as críticas endereçadas à política do Estado hebreu pelos democratas não visam à deslegitimação. Pelo contrário, este debate aberto, até mesmo virulento, é um dos elementos constitutivos da legitimidade de Israel (JOFFRIN, In. Libération, 7/06/2010).

Assim, é a aplicação de um mesmo tratamento às ditaduras e às democracias que Joffrin qualifica de injusta. "Uma equidade de aparência" consistiria em rejeitar toda forma de distinção entre esses regimes antitéticos. O que é precisamente equitativo neste contexto - às avessas das ideias preconcebidas de "dois pesos, duas medidas" - é que o jornalista inverte as conotações axiológicas. Elas passam da condenação para uma avaliação melhorativa ${ }^{12}$.

Enfim, os indivíduos, as coletividades ou os meios de comunicação também puderam protestar, não contra a aplicação da regra, mas contra as modalidades falaciosas de sua operacionalização. Um dos alvos mais frequentes de suas críticas é, no corpus deste estudo, a "indignação seletiva"13. Le Monde, de 15 de junho de 2015, insiste, em um de seus editoriais, no fato de que "todos os chefes de Estado e chefes de guerra julgados ou processados pelos juízes instalados em Haia são africanos" e thes opõe o silêncio do Tribunal Penal Internacional quanto às "autoridades sírias", "generais birmaneses", "rebeldes ou milicianos pró-governos sul-americanos e outros déspotas e saqueadores do planeta". Uma jornalista do Figaro, em 9 de março de 2010, reflete, em um editorial intitulado "Indignação seletiva", sobre a oscilação dos meios de comunicação entre "estado de alerta máximo" e "serviço mínimo", apesar do fato de que a priori trata-se de "informações de igual importância": o "saque de uma igreja" passa "quase despercebido", mas o ataque a uma mesquita ou a uma sinagoga merecem "eco retumbante"...

12 Claire Bouglé-Le Roux defende um ponto de vista idêntico ao desenvolvimento consagrado abaixo à imparcialidade do estado laico.

13 Cf. o blog de Daniel Salvatore Schiffer, "A l'alarme, citoyens! », no Mediapart (10.02.2012), no artigo "La dictature au Maroc : silence, on censure, emprisonne, torture et tue !" : Isto é o que as consciências críticas mais honestas e lúcidas, mas também mais livres do Hexágono, nomeada assim oportunamente, mas desta vez em sentido pejorativo, a "indignação seletiva" ou, ainda, o engajamento à geometria variável". 
EID\&A - Revista Eletrônica de Estudos Integrados em Discurso e Argumentação, Ilhéus, n. esp. ADARR, mai.2016.

Combater a iniquidade ou os dois pesos, duas medidas aplicados no caso de "indignação seletiva" permite reconstruir as condições de possibilidade de uma racionalidade prática equitativa.

A invocação jurídica do "precedente" não está imune a esse sentimento de mal-estar ético. O juiz é livre para distanciar-se dele se a aplicação dessa norma não permitir que se levem em consideração as diferenças sóciohistóricas que the parecem essenciais. Isto em nome de uma concepção prática de justiça que coloca a sua insatisfação acima da aplicação mecânica da regra e decide dar primazia à sua concepção de equidade. Assim, implementase um "racionalismo" transformado por uma dimensão "crítica" plenamente assumida e que "transcende a dualidade julgamentos da realidade julgamentos de valor" (TA, p. 681-682), "regra de justiça" formal atemporal e "regra justa" prática e "histórica".

2. Os estudos de casos: a regra da justiça no campo de um "racionalismo crítico"14

A fórmula "dois pesos, duas medidas" expõe de maneira eficaz a revolta e a indignação daqueles que reivindicam a aplicação da regra de justiça. É por meio de seus discursos de protesto que expectativas éticas da regra são mais claramente perceptíveis. Uma coluna no site nativo Rue89 define a sua identidade nestes termos:

"os mal amados", "aqueles que têm medo do amanhã por causa de seu físico, de seu nome, de seu sotaque, de suas condições materiais, dos limites de suas qualificações... árabes, negros, judeus, muçulmanos, pobres, pessoas com deficiência, sem-tetos, idosos, moradores dos guetos, camponeses sem assistência médica, homossexuais, estrangeiros ilegais, estrangeiros de todas as cores e de todos os gêneros, no sentido literal e figurado. (AL-HAKKAK. In. Rue89, 14.01.2015).

A necessidade de "reconhecimento" político e social, na qual Chaumont $(1997$, p. 13,18) vê uma espera existencial fundamental, viria de "uma trágica história de humilhação, de ocultações e de estigmatizações", vividas coletivamente ou individualmente ${ }^{15}$. Todos reivindicam a atribuição de um "mesmo status", dos "mesmos direitos" e das "mesmas oportunidades de acesso a uma proteção equivalente" (HENRY In. Rue89, 09.09.2008).

14 Cf. TA, p.681.

15 Cf. Ricoeur (1995, p.14-15): "A virtude da justiça é estabelecida em uma distância em relação ao outro [...]. O outro, na amizade, é você, o outro, de acordo com a justiça, é cada um”. 
EID\&A - Revista Eletrônica de Estudos Integrados em Discurso e Argumentação, Ilhéus, n. esp. ADARR, mai.2016.

Propomos apresentar abaixo uma sequência de argumentos que apostam na crítica da aplicação da regra. Os exemplos típicos do corpus analisado circulam em torno de quatro problemáticas centrais: balanços de vítimas "assimétricos"; amálgama ou deslocamento de evocação de duas situações semelhantes para um ato de nomeação assimilador; o dever de "imparcialidade" do Estado; a equivalência das acusações de "blasfêmia" e "antissemitismo" ou de "terrorismo". Trata-se, nesses quatro casos, como indicam os lexemas ou os enunciados típicos de prenúncio, da denúncia de um “desequilíbrio", de "disparidades" ou de "tratamento desigual” "que a razão não explica" . "Então, investigaremos o que os diferentes autores chamam de diferenças entre os grandes princípios e o que acontece "em um campo específico"17 ou, ainda, entre a "aplicação integral e global" de uma "Convenção" internacional e o que acontece "nos fatos", ou entre a justiça "universal em seus princípios" e sua aplicação "à geometria variável” "em ação" e, finalmente, entre as "dificuldades" do "cotidiano" e a aspiração do "ideal" 18 .

2.1. Imparcialidade e/ou equidade: o caso de balanços de vítimas "assimétricos"

Frequentemente, o balanço de vítimas ocupa na mídia a função de apêndice, sendo continuação da reportagem ou integrado a um dossiê, mas pode também constituir um tipo de artigo completo. Ele restringe-se simplesmente a identificar as vítimas de ambos os lados de um conflito e pratica uma retórica estritamente factual, em que as indicações numéricas são um fim em si e constituem a própria informação, já que não se faz qualquer referência ao contexto sócio-histórico. Este tipo de balanço pode ser considerado como o máximo da imparcialidade. Um exemplo típico foi extraído do jornal 20Minutes, de 4 de agosto de 2014: o artigo “"Bordure protectrice': les 10 chiffres qui résument le dernier conflit israélo-palestinien”. O texto zela por respeitar a apresentação igual de perdas nos dois campos, a disposição tipográfica semiotiza a oscilação entre dois polos simétricos: o

16 Cf., respectivamente, os dois fóruns a seguir: Perrotin, 2015: "Explosion des actes islamophobes. Et derrière, quelles condamnations ?", e Henry, 2008: “Asile: en Europe, c'est deux poids deux mesures".

17 Este tipo de descrição profana confirma a distinção de Perelman entre a inclinação formal da finalidade universal da regra de justiça e sua inclinação sócio-histórica prática ou entre o racional e o razoável.

18 Cf. “Indispensable justice internationale", Le Monde (15.06.2015); 
EID\&A - Revista Eletrônica de Estudos Integrados em Discurso e Argumentação, Ilhéus, n. esp. ADARR, mai.2016.

artigo é composto por cinco pares de parágrafos equivalentes opondo a situação em Gaza e em Israel. Nenhum comentário acompanha os números apresentados. A avaliação dos balanços, no entanto, emerge assim que eles são colocados em seu contexto sócio-histórico, provocando muita controvérsia ${ }^{19}$. Seu propósito inicial - refletir sobre os fatos tal como eles são, midiatizar dados informacionais - desencadeia debates intensos, que se fundamentam na regra de justiça. Os dados evidenciam uma desproporção impressionante entre o número de vítimas em cada um dos campos e que faz com que o público tire suas próprias conclusões: um dos dois campos claramente usou de violência letal injustificável. Seria eticamente impossível abster-se de qualquer avaliação e limitar-se a uma abordagem quantitativa ${ }^{20}$ do balanço, separando fatos e comentários. A desproporção entre o número de vítimas entre os dois campos torna obrigatória à abordagem qualitativa. $O$ formalismo da regra entraria em contradição com a realidade esmagadora da guerra e da morte. A preocupação com equidade é substituída aqui pela preocupação com a justiça. O repórter de guerra belga, Bruno Stevens, comentou sobre a assimetria do balanço das vítimas libanesas e israelenses em uma coluna do Libération (05.09.2006) $)^{21}$ : "apresentar de maneira equivalentemente as coisas que não são, dar o mesmo espaço aos quarenta civis israelenses mortos e aos milhares de civis libaneses mortos é uma farsa [...] uma proporção de 1 para 25 denota uma assimetria manifesta que é conveniente reportar e sobre a qual é eticamente imperativo se debruçar" (grifo meu). Portanto, aqui, passa-se de um olhar objetivo quantitativo para uma crítica subjetiva qualitativa e avaliativa ${ }^{22}$. Neste caso, os lexemas

19 Cf., Angenot, 2012, p. 64: "Quais são os requisitos para que a regra da justiça seja colocada como condição concreta de gozo da justiça? Esta regra deve, a fim de ser aplicada, ser avaliada e explicitada por outros topoi, ou seja, outras regras emaranhadas que revelem vozes tópicas diversas: tópica da qualidade e da quantidade, do remediável e do irremediável, dos idênticos, dos comparáveis/semelhantes, dos recíprocos e dos complementares".

20Cf. ED, p. 169. Perelman enfatiza que o ponto de vista racionalista clássico valoriza "o que é universal" e "quantitativamente mais importante".

21 A polêmica da qual Stevens participa é analisada por Koren (2011), "Sobre a racionalidade e/ou irracionalidade dos polemizadores: certezas e incertezas". Libération midiatiza a posição do sociólogo Shmuel Trigano que defende a tese de dois pesos, duas medidas na mídia francesa quando se trata de Israel. Bruno Stevens a critica invocando a imparcialidade do fotojornalista. Michel Tubiana, Presidente Honorário da Liga dos Direitos Humanos, argumenta que há dois aspectos da aplicação da regra da justiça: a reivindicação de não fazer diferenças entre o Estado de Israel, descrito como "Estado como outro qualquer" e outros países em guerra, mas também de não fazer a distinção entre as vítimas em nome de um princípio universal fundamental: "o cadáver" da "criança" que vemos nas fotos "é principalmente a de um inocente sem nacionalidade".

22 Cf. ER, p. 116: "Os defensores do plano Marshall, criado para a Europa [...] e concebido como um plano de reconstrução, pretendiam que uma redução de crédito de $25 \%$ o transformasse em um programa de assistência: uma diferença quantitativa foi apresentada como uma diferença de natureza. Em que momento uma diferença quantitativa se torna uma diferença qualitativa [...]? 
EID\&A - Revista Eletrônica de Estudos Integrados em Discurso e Argumentação, Ilhéus, n. esp. ADARR, mai.2016.

axiológicos pejorativos "farsa" e "assimetria" o enfatizam de maneira eloquente. De fato, é difícil não sentir um profundo mal-estar face a tal desproporção.

Pode-se, portanto, inferir que nenhuma crítica pode refutar o balanço de vítimas assimétrico, mas a relevância do argumento de Perelman, de que tudo (ou quase tudo) é discutível no campo da argumentação, é plenamente confirmada por um dos artigos que fazem parte do corpus deste estudo. Trata-se de um texto, intitulado "Desproporcional", publicado na internet por um blogueiro, Alain Legaret (2009), que contesta a relevância e a legitimidade do argumento da assimetria simulando a aplicação formal da regra de justiça até $\mathrm{o}$ absurdo $^{23}$. Isso envolve, em primeiro lugar, a definição de "desproporcional" como "palavra usada para expressar seu desapontamento quando não há número suficiente de judeus mortos". A argumentação propõe, em seguida, entre outros, os dois seguintes raciocínios: 1 - "dado que há na terra cerca de cem vezes mais muçulmanos do que os judeus", "quando os islamistas do Hamas [...] assassinam 18 judeus no nome de Alá, os judeus em troca devem matar 100 vezes mais", "o que logicamente será uma resposta proporcional”, 2 - "Um judeu por mil árabes. É o número de prisioneiros que eles exigem em troca do refém Guilad Shalit. Por que ainda nenhuma queixa de pacifistas foi ouvida, se poderia supor que esse coeficiente é aquele que eles suporiam mais aproximar-se das proporções aceitáveis?"

A ironia e o argumento pelo ridículo tentam, então, provar, ao contrário, que a objetividade das indicações numéricas não neutraliza os posicionamentos ideológicos e pode, até mesmo, servir como fundamento. Ninguém estaria a salvo de "dois pesos, duas medidas", como evidenciado pela "indignação" "seletiva" dos "pacifistas". Perelman e Olbrechts-Tyteca também anteciparam uma possível crítica ao formalismo excessivo da regra por meio de um "humor negro". O TA cita um fragmento de A vigésima quinta hora, de Gheorghiu, cujo tom é semelhante ao do blogueiro:

Estas frações de homens que não têm mais do que pedaços de carne, recebem a mesma quantidade de comida que os prisioneiros em plena posse de seus

Precisa-se de uma decisão que permite a passagem que transforma uma diferença de grau na natureza". Stevens, portanto, prefere uma abordagem ética equitativa a uma abordagem formal justa.

23 Quanto ao papel do ridículo, do absurdo e da ironia para antífrase na argumentação, ver Perelman e Olbrechts-Tyteca, 1983, p.276-282. 
EID\&A - Revista Eletrônica de Estudos Integrados em Discurso e Argumentação, Ilhéus, n. esp. ADARR, mai.2016.

corpos. Esta é uma grande injustiça. Proponho que estes prisioneiros recebam porções de alimentos em proporção à quantidade de corpo que ainda possuem (TA, p. 296).

Esses posicionamentos extremos não são, no entanto, a norma. A maioria dos críticos tentam conciliar as abordagens quantitativa e qualitativa e passar da esfera dos grandes princípios de justiça absoluta a razoabilidade e equidade. Daniel Schneidermann evoca os balanços russos e americanos das vítimas da Segunda Guerra Mundial no site nativo da La Gazette d'arrêt sur images, de 6 de junho de 2014. O jornalista argumenta em favor da "equidade memorial", que deveria homenagear, como parte das comemorações do desembarque, os 11.000 .000 de soldados soviéticos mortos durante a Segunda Guerra Mundial, enquanto que apenas 184.000 soldados norteamericanos morreram no front, ou seja, "para um soldado norte-americano morto, 60 soldados soviéticos mortos". No entanto, ele imediatamente acrescenta que "essa desproporção não retira em nada o heroísmo das tropas anglo-americanas que desembarcaram debaixo das metralhadoras dos bunkers alemães" e convida o público a compreender as abordagens quantitativa e qualitativa como abordagens complementares indissociáveis. Ser justo, neste caso, é se recusar a basear o ato de julgar no grau de simetria dos dois campos, é sublinhar a desproporção do número de vítimas americanas e soviéticas, mas também, simultaneamente, a presença, nos dois campos, de valores não mensuráveis nem qualificáveis como coragem, solidariedade e heroísmo. Assim, Schneidermann recusa-se a fazer distinção entre as vítimas e alimentar a "concorrência".

"Todos os sofrimentos são válidos" e merecem ser reconhecidos, segundo a opinião do historiador Alfred Grosser em um artigo publicado em La Croix, de 25 de janeiro de 1995, intitulado "Comparar Auschwitz". O pesquisador recusa-se a fazer distinções entre as vítimas de genocídio e a validar a tese da singularidade da Shoah. Tratar todas as vítimas da mesma maneira é, na opinião dele, a condição de possibilidade de uma memória "fecunda", "geradora de paz e justiça"24. A ética surge neste discurso no quadro das práticas discursivas que orientam o auditório, como indicado pelos epítetos "fecunda" e "geradora", em direção a uma passagem à ação destinada a contribuir com erradicação da violência. Esta é também a posição

24 Ver também, Rony Brauman, Disponível em: http://www.msf-crash.org/drive/d92c-rb-1995-y-a-til-une-hierarchie-de-la-souffrance-_fr-art-p.4_pdf : "Porque o fenômeno político que produziu Auschwitz foi único, não significa que ele seja realmente incomparável, muito menos que o sofrimento dos deportados não tenha um equivalente" (1995, p. 3) 
EID\&A - Revista Eletrônica de Estudos Integrados em Discurso e Argumentação, Ilhéus, n. esp. ADARR, mai.2016.

do retórico Ekkehard Eggs (2014, p. 147), que formula o desejo, no final de um estudo sobre o exemplo histórico (uma variação do "precedente") - as violências em massa e os Justes da Shoah - que a razão prática contribui, numa modesta escala, para orientar o auditório em direção a "atividades" ao mesmo tempo "cognitivas" e "reativas" "permitindo evitar ou impedir atos de violência em massa".

\section{2. "Laicidade" e "imparcialidade" do Estado}

Os ataques em janeiro de 2015 contra os jornalistas do Charlie Hebdo e contra os clientes do Hyper Cacher aumentaram dez vezes, nos meses seguintes, o impacto do debate sobre um dos valores essenciais da República: a laicidade. Ela está relacionada com o dever de imparcialidade do Estado pelas ligações essenciais. Na França, não se deve fazer distinção entre as religiões e deve-se respeitar o direito de cada cidadão a uma "autonomia ética real", segundo um artigo de Peña-Ruiz, no Le Monde Diplomatique, de fevereiro de 2014, intitulado Laïcité et égalité, leviers de l'émancipation. "A valorização excessiva das diferenças" levaria à guerra e à violência na sociedade civil. O Estado deve, portanto, tratar todas as comunidades, religiosas e laicas, da mesma forma. Ele deve, portanto, manter-se neutro e "imparcial" (Ibidem) bem como desempenhar as suas funções de garantir a liberdade e a segurança de todas as comunidades. Deve, diz o autor, recusarse a jogar o jogo daqueles que bradam o argumento de que há "dois pesos, duas medidas" e não diferenciam as vítimas de atos antissemitas daquelas de uma islamofobia cada vez mais preocupante. "Nós nos reunimos sobre os princípios da laicidade para que eles sejam respeitados na prática e por todos", lemos em Daniel Cassiaux, no Mediapart de 29 de março de 2015. "Nós nos reunimos na fraternidade, cessando as políticas que fazem explodir as desigualdades". Esta é também a opinião dos leitores da internet de Le Figaro, de 7 de julho de 2015, que resume os pontos de vista sobre a polêmica a favor ou contra a imparcialidade do Estado, afirmando: "Noite de Ramadan: 'para respeitar a laicidade, não celebremos nenhuma festa religiosa'; A laicidade é saber viver juntos".

A "Noite do Ramadan", realizada ultimamente nas instalações da Prefeitura de Paris, vem, de fato, suscitar, na mesma edição de Le Figaro, de 6 de julho de 2015, uma polêmica, opondo a denúncia de uma aplicação de "geometria variável" do princípio da imparcialidade do Estado a um elogio 
EID\&A - Revista Eletrônica de Estudos Integrados em Discurso e Argumentação, Ilhéus, n. esp. ADARR, mai.2016.

paradoxal da parcialidade. Dois universitários defendem pontos de vista opostos sobre um paralelo entre presépios expostos na época do Natal em prefeituras na Provence e em Vendée e a "Noite do Ramadan", que aconteceu em Paris. Madeleine de Jessey (Le Figaro - 06.07.2015) se surpreende com o "dois pesos, duas medidas" que conduz "aqueles que se indignam com a exposição de um presépio no Natal" a "achar a operação da prefeitura de Paris absolutamente normal", apesar da "justiça e do bom senso". Claire Bouglé-Le Roux (Le Figaro - 07.07.2015) diz o contrário, que "Ionge de condenar a 'laicidade à geometria variável', trata-se de fazer o seu elogio ${ }^{25}$, formulando o desejo de que ela garantisse à religião cristã, historicamente enraizada na França, um estatuto privilegiado, devido ao seu elevado valor cultural". Não instituir um regime de favor, do qual o cristianismo seria o beneficiário, na sua opinião, seria contrário à história da França e ao respeito de suas tradições, seja a pessoa crente ou ateu. Arriscaríamos levar "à negação e à renúncia implícita daquilo que constitui o fundamento da nossa história nacional".

Mas o que muitos cidadãos se perguntam: o que ocorre, no caso da liberdade de expressão - outro valor laico igualmente primordial - quando uma destas religiões é objeto de críticas violentas? Fiel ao axioma da imparcialidade e da neutralidade, o Estado laico, como lembram jornalistas ou personalidades entrevistadas, concede a cada um o direito de criticar a religião ou mesmo de recorrer à blasfêmia. No entanto, ele intervirá se crentes forem insultados ou se houver incitação ao ódio e a atos de violência mortal ${ }^{26}$ contra eles. A seguir, dois estudos de casos que exploram os meandros da aplicação da regra da justiça nesse tipo de debate.

\subsection{Quando aplicar a regra da justiça é nomear da mesma forma: o caso do amálgama}

Os exemplos discutidos abaixo confirmam a hipótese segundo a qual "idêntico" poderia ser parafraseado por: tudo o que é dito sobre um deve também ser sobre o outro, ou, neste caso, nomear da mesma maneira dois $\mathrm{X}$ que o locutor considera que são "intercambiáveis", "equivalentes" ou idênticos (ED, p. 109). O raciocínio utilizado é que $X=Y$, sendo "violência,

25 Cf. Angenot, 2012, p.64: "Os conceitos-contraditórios de justas desigualdades (agora discriminação positiva) e equalização injusta vêm aqui recordar uma aporia, que sempre foi uma pedra no sapato de todos os pensamentos cívicos e sociais".

26 Cf. Boris Manenti, L’OBS Societé (20.01.2015) e Sonya Faure, Libération (14.01.2015). 
EID\&A - Revista Eletrônica de Estudos Integrados em Discurso e Argumentação, Ilhéus, n. esp. ADARR, mai.2016.

terrorismo, subúrbios" = "religião muçulmana"27, então é legítimo incluí-los em uma mesma e única categoria, bem como apresentá-los como intercambiáveis. $\mathrm{X}$ e $\mathrm{Y}$ encarnam o inimigo único e, portanto, merecem o mesmo tratamento. Tentaremos, assim, afirma André Glucksman, no Le Monde (03.03.2006), demonstrar que a "negação" da existência de Auschwitz e da "profanação de Maomé" são dois crimes da mesma ordem, sob o pretexto de que se trata de dois casos de "crenças" "igualmente desrespeitadas". Por isso, haveria uma assimilação falaciosa aqui entre "verdade de fato" e "profissão de uma fé", história e religião, efetuada pelo recurso a uma qualificação comum e idêntica, "desrespeitada".

Mas o amálgama mais proveitoso neste corpus foi feito pelo comediante Dieudonné na declaração "Eu me sinto Charlie Coulibaly". Engo, no Mediapart, de 12 de janeiro de 2015, a qualifica como "estranha mistura" entre "um ou mais terroristas notórios" e os "defensores da liberdade do Charlie Hebdo". Por trás da fórmula "Charlie Coulibaly", como uma palavra composta por extratos de outras palavras e que representa o apagamento de qualquer diferença entre "liberdade de expressão" (os jornalistas do Charlie Hebdo) e o ato terrorista criminoso (Coulibaly é o sobrenome de um dos terroristas), aproveita-se de uma aplicação falaciosa da regra de justiça ${ }^{28}$. Dieudonné reuniu em uma mesma qualificação aquilo que the parece equivalente: 0 terrorista Coulibaly e os jornalistas do Charlie Hebdo são vítimas de seus pontos de vista e pagaram com suas vidas. Por outro lado, não é a primeira vez que ele usa esse tipo de amálgama. Ele já havia usado em 2003, recordam alguns jornalistas, a fórmula "Isra-heil", que é a contração de Israel com a saudação nazista "Heil Hitler". O neologismo, a justaposição e a figura de consonância por paronomásia contribuem para a nazificação de Israel. A fórmula, implicitamente, afirma a equivalência de Israel e do Estado nazista, paradigma do mal absoluto, e também incita implicitamente a submetê-los ao mesmo tratamento.

Muitos jornalistas se sentem constrangidos, neste contexto, de responder para os leitores ou internautas que "se perguntam por que 'Charlie' é defendido enquanto Dieudonné é punido" por causa da amálgama "Charlie Coulibaly", por "apologia ao terrorismo" (Libération, de 14 de janeiro de 2015, "Querido D., não há dois pesos, duas medidas"). O fato de essa questão ser

27 Cf.: http://www.ina.fr/contenus-editoriaux/articles-editoriaux/islam-et-amalgame/ 28 Cf. Koren (2012, p. 93-105), um exame crítico feito sobre as diversas práticas discursivas que têm amálgamas ou analogias falaciosas como questão. 
EID\&A - Revista Eletrônica de Estudos Integrados em Discurso e Argumentação, Ilhéus, n. esp. ADARR, mai.2016.

tão frequentemente colocada, entre outras coisas, prova a importância do papel formal da regra na regulação de raciocínio sobre o justo e o equitativo. Fazer tal tipo de pergunta é abordar o evento por um ângulo de uma semelhança considerada, num primeiro momento, como preocupante. Tratase, de fato, em ambos os casos, da profissão de humorista, da retórica da sátira e a liberdade de expressão. Mas, a pergunta foi feita na esfera da "razão histórica", da argumentação dos valores e não naquela dos grandes princípios abstratos. Os jornalistas também se esforçam, como, aliás, os políticos da época, para refutar a simetria aparente invocando diferenças decisivas. Colocar a apologia ao terrorismo e o ato de ridicularizar o fundamentalismo muçulmano no mesmo nível é uma maneira de transgredir a regra da justiça considerada não equitativa. Os jornalistas tentam fazer compreender e aceitar, lembrando que a liberdade de expressão termina onde começa o apelo ao ódio e à violência. Quanto à pergunta se os jornalistas do Charlie Hebdo são como o comediante Dieudonné, Libération responde que "o humor está do lado da vida. A liberdade de expressão não é invocar o ódio", nem serve para a justificativa implícita ao ataque. Sobre isso, dois jornalistas do Monde, em um artigo de 14 de janeiro de 2015, intitulado “'Charlie', Dieudonné ...: o que limita a liberdade de expressão?", resumem que "a liberdade de expressão não permite incitar publicamente a morte do outro, nem fazer apologia a crimes de guerra, crimes contra a humanidade, nem incitar o ódio contra um grupo étnico ou nacional dado".

\subsection{Lógica e razão prática: análise e denúncia do "paralelo perigoso"}

A fórmula "dois pesos, duas medidas" é apresentada em um artigo do Mediapart, de 27 de janeiro de 2015, como "uma expressão que é uma armadilha e é perversa", cuja aplicação representaria uma verdade perigosa para a vida política e social na França. Este perigo, afirma o autor, Michael Hajdenberg, deve-se ao fato de a fórmula estar fundamentada em "paralelos perigosos e não controlados" que estruturam "o debate em torno da concorrência entre vítimas" e, assim, favoreceriam o antissemitismo e a "islamofobia", em vez de contribuir para a sua erradicação ou para a diminuição de sua violência. Os próprios jornais de circulação nacional contribuem para a transformação da fórmula no quadro de análise incontornável, orquestrando debates e polêmicas públicas. "A expressão se torna sem sentido, aponta ele, nesta comparação entre um conflito territorial 
EID\&A - Revista Eletrônica de Estudos Integrados em Discurso e Argumentação, Ilhéus, n. esp. ADARR, mai.2016.

no Oriente Médio e atos antissemitas na França no ano 2000". Mas há algo ainda mais grave: trata-se da assimilação do conflito Israel-Palestina e os atentados antissemitas colocados originalmente no mesmo plano pelos jovens dos subúrbios que escandem a fórmula "dois pesos, duas medidas". Essa assimilação seria reforçada e legitimada, sem a menor distância crítica, por parte dos jornais de circulação nacional. Os homens do poder não denunciam os excessos dos ataques israelenses contra os palestinos, mas se indignam quando os judeus da França são vítimas de violência antissemita. Uma jornalista do Le Monde insiste, acrescenta o autor, no sentimento de "dois pesos, duas medidas" que "toma os subúrbios", enquanto o exército israelense dispara contra palestinos, quando se refere a "mais de 120 atos de violência contra sinagogas ou lugares simbólicos da comunidade judaica em um mês". O raciocínio subjacente é o seguinte: os judeus que são solidários ao Estado de Israel não devem se surpreender ao serem alvo de atentados. No entanto, o Estado os protege e reage muito mais a esses atos de violência do que àqueles dirigidos à comunidade muçulmana. Se a mídia se recusasse a praticar esse tipo de raciocínio, evitaria "ninhos antissemitas" e o incentivo à concorrência entre as diferentes vítimas, além de apoiar uma "luta contra a islamofobia", que "definitivamente merece apoio".

$\mathrm{O}$ artigo, finalmente, toma uma posição em relação a um grande debate muito próximo àquele desencadeado pela crítica à declaração "Eu me sinto Charlie Coulibaly", mas que confronta agora noções de "blasfêmia" e "ódio contra os judeus como seres humanos" e não mais a questão da "liberdade de expressão" e de "apologia ao terrorismo". O autor rejeita qualquer forma de validar oscilações de igualdade entre esses dois polos, a fim de salientar que, na França, "se é proibido qualquer insulto aos crentes, é permitido zombar das religiões", o que exonera o Charlie Hebdo. Já o Holocausto, ridicularizado pelo humorista, não é "um dogma religioso, mas um fato histórico". É, portanto, perfeitamente legítimo levar Dieudonné à justiça por incitação ao ódio racial. A assimilação de duas noções de ordem totalmente diferentes blasfêmia por um lado e antissemitismo por outro - seria um erro a se evitar a todo o custo e a se analisar, se quisermos acabar com o incômodo que suscita em uma parte da opinião pública o argumento de "dois pesos, duas medidas" e as dificuldades de aplicação de um tratamento justo e equitativo.

O filósofo André Comte-Sponville defendeu um ponto de vista semelhante em entrevista ao Le Monde em 12 de março de 2015, que foi 
EID\&A - Revista Eletrônica de Estudos Integrados em Discurso e Argumentação, Ilhéus, n. esp. ADARR, mai.2016.

intitulada "A blasfêmia faz parte dos direitos humanos, mas não faz arte das boas maneiras". A ideia defendida por ele é de que "Charlie Hebdo 'caricatura' o profeta" de um lado, "Dieudonné 'caricatura' os judeus" de outro. A pergunta que Le Monde lhe fez foi a seguinte: neste caso, há "dois pesos, duas medidas", já que Dieudonné foi condenado publicamente e levado à justiça enquanto que os jornalistas do Charlie Hebdo foram elogiados pelo mesmo ato? A resposta do filósofo vai claramente no mesmo sentido do artigo de Mediapart: "a lei proíbe a incitação ao ódio racial, logo, notadamente, o antissemitismo. Ela não proíbe a blasfêmia". "Ódio racial" e "blasfêmia" não são, na opinião dele, conceitos próximos ou idênticos, de mesma ordem ${ }^{29}$; não há nenhuma reciprocidade ou simetria entre eles; eles não são intercambiáveis, mas "claramente diferentes". A razão prática permite, portanto, distinguir entre "delito" e "liberdade de opinião" e concluir que é logicamente inconsistente considerá-los como equivalentes. A "denúncia de um grupo étnico" não pode ser colocada no mesmo plano que a "caricatura de uma personalidade religiosa" ${ }^{30}$. A resposta do filósofo está, portanto, situada no cruzamento do formalismo racionalista da regra de justiça com o regime de racionalidade prática. O primeiro permite designar a "caricatura" como um objeto simétrico comum de um ato de julgamento para justificar o mesmo tratamento; o segundo permite estabelecer que não seria equitativo não levar em consideração as diferenças essenciais entre os alvos destas caricaturas e suas expectativas em um contexto sócio-histórico que envolve questões éticas da vida e da morte.

\section{Regra de justiça e engajamento}

A aplicação formal da regra de justiça permite, por sua definição: tratar dos seres ou das situações idênticas da mesma forma - o que suspende primordialmente qualquer forma de julgamento avaliativo. Por isso, exige que quem a aplica mostre imparcialidade. Vimos, no entanto, que isso nem sempre é possível ou desejável e que existem casos em que ela parece contradizer a demanda ética pelo justo e pelo equitativo. A argumentação desses valores

29 ER, p.116.

30 Cf. Émilie Brouze, no Rue89, de 14.01.2015. A jornalista cita esta declaração de Manuel Valls: “O racismo, o antissemitismo, a negação do Holocausto, a apologia ao terrorismo não são opiniões, são crimes". 
EID\&A - Revista Eletrônica de Estudos Integrados em Discurso e Argumentação, Ilhéus, n. esp. ADARR, mai.2016.

leva, então, a rever a questão da relação entre justiça, julgamento e "engajamento" (TA, p. 78-83).

A oscilação entre dois polos opostos é uma das premissas básicas da impressa. Ela representa a recusa de avaliar e priorizar pontos de vista opostos e gera, portanto, a impressão de imparcialidade. Assim, qualquer ator de um conflito será tratado da mesma maneira (KOREN, 2001, p. 177-200). O repórter de guerra Bruno Stevens, citado acima quando falamos dos balanços das vítimas, enfatiza veementemente que ele estava presente em Jenin com os palestinos, durante o cerco da cidade pelo exército israelense, mas "presente também durante os desprezíveis ataques suicidas nos ônibus na Rua Jaffa em Jerusalém". Ele demonstra, no entanto, na sua análise da desproporção dos balanços de vítimas, que a imparcialidade absoluta às vezes é uma escolha contrária à equidade e, portanto, a outro valor ético essencial. O jornalista se contradiz tendo esse tipo de discurso? Será que ele defende uma concepção de imparcialidade de "geometria variável" ou de "duas medidas"? Suas duas tomadas de posição antitéticas provam simplesmente que o ato de julgar depende, no campo da razão prática, do contexto sóciohistórico e da regulação de argumentos relacionados do tipo quantitativo (balanços de vítimas objetivas em tempos de guerra) e / ou qualitativa (desproporção, crimes contra civis, indignação).

O "engajamento neutro" (KOREN, 2004) da ética jornalística pode, contudo, levar a justapor um discurso favorável e um discurso contrário, depois, pode se esquivar e, no momento posterior, dividir estes discursos a fim de respeitar a liberdade de pensamento do auditório. Mas há ainda imparcialidade e neutralidade quando uma das teses justaposta é, por exemplo, o heroísmo dos resistentes Lucie e Raymond Aubrac e outro é sobre aqueles que os suspeitam de serem traidores? Trata-se de teses equivalentes? O verdadeiro e o falso são teses de igual valor? A renúncia da não divisão é um modo válido de aplicação da regra de justiça ou uma de suas limitações, já que o respeito à honra do Outro não foi levado em consideração (KOREN, 2001)?

Os jornalistas do corpus deste estudo e os autores aos quais eles dão voz analisam e criticam a tomada de posição de seus contemporâneos, apesar do princípio fundamental da objetividade da informação e da separação dos fatos e comentários. Então, eles param, neste caso, de sacralizar a suspensão do julgamento e provam, assim, que, na verdade, é impossível manter-se neutro quando se trata de valores verdadeiros como os outros. A tentativa da NR de 
EID\&A - Revista Eletrônica de Estudos Integrados em Discurso e Argumentação, Ilhéus, n. esp. ADARR, mai.2016.

conceituar e legitimar a racionalidade axiológica é, portanto, uma contribuição essencial para a transição do pensamento para a ação.

\section{Conclusão}

A fixação e a argumentação da regra de justiça na trama discursiva de conflitos ou controvérsias políticas ou sociais contribuem para validar algumas verdades retóricas essenciais: a suspensão do ato de julgar não é uma garantia absoluta de equidade, mas uma escolha também refutável como as outras; pode ser necessário avaliar, hierarquizar e dividir quando agir é uma necessidade. Os grandes princípios morais constituem um quadro comum para a gestão da vida política e social, mas eles estão submetidos à complexidade das situações sócio-históricas com as quais devem se compor. Isso, às vezes, leva os indivíduos, os juízes e as comunidades a colocarem a equidade acima da justiça e a considerarem a imparcialidade como uma forma de injustiça.

A regra aumenta igualmente a visibilidade de outra verdade retórica primordial: o que conta acima de tudo é a função persuasiva do raciocínio. $O$ argumento do precedente não deve sua força nem a importância que a NR Ihe acorda ao respeito de uma verdade abstrata universal, mas a uma "razão histórica", prática que incentiva o auditório a considerar decisões anteriores que já foram validadas por juízes em circunstâncias semelhantes.

A regra da justiça confirma enfim a importância ética fundamental da relação com o Outro. Como destacam, respectivamente, Danblon (2013, p. 135) e Eggs (2014, p. 147), ser justo implica ser capaz de realizar uma "abertura em direção ao outro", e esta forma de "criatividade" consiste em buscar soluções para os problemas políticos e sociais "para atender às novas necessidades institucionais que serão impostas aos cidadãos". Ser justo implica, destaca o retórico, "reconhecimento do outro em sua alteridade, engajamento para garantir ao outro o que se espera que ele nos garanta, ou seja, uma vida humana feliz". Esse tipo de reciprocidade não é certamente aplicável, nem absolutamente garantido, mas permite certamente manter no razoável e resolver, ainda que imperfeitamente, o fato paradoxal de que os grandes princípios racionais constituem, às vezes, um obstáculo para a justiça política e social. 
EID\&A - Revista Eletrônica de Estudos Integrados em Discurso e Argumentação, Ilhéus, n. esp. ADARR, mai.2016.

\section{Referências}

AL-HAKKAK, G. Ainsi, vivre ensemble sur le sol français aurait un sens nouveau, sublime, savoureux. Rue89 (14.01.2015). Disponível em: http://rue89.nouvelobs.com/2015/01/14/ainsi-vivre-ensemble-sol-francais-aurait-sensnouveau-sublime-savoureux-257089. Acesso em:15.08.2015.

AMOSSY, R. Faut-il intégrer l'argumentation dans l'analyse du discours? Problématiques et enjeux. Argumentation et Analyse du Discours [online], n.9, 2012. Disponível em http://aad.revues.org/1346. Acesso em 14.07.2015.

. Les enjeux du 'déraisonnable' : rhétorique de la persuasion et rhétorique du dissensus. In. MEYER, M. ; FRYDMAN, Benoît (éds.). Chaïm Perelman (1912-2012). De la nouvelle rhétorique à la logique juridique, Paris : PUF, 2012.

ANGENOT, M. Le rationnel et le raisonnable Sur un distinguo de Chaïm Perelman. Discours Social, volume 42-2012, Montréal : Presses de l'université McGill, 2012.

BAZIN DE JESSEY, M. Nuit du Ramadan à la mairie de Paris ou la laïcité à géometrie variable. Le Figaro (06.07.2015). Disponível em: http://recherche.lefigaro.fr/recherche/access/lefigaro_fr.php?archive=BszTm8dCk78a tGCYonbyzjXRdS2HXVSzbpjlUh1N6GHq8BFvLCHrXHfÜ1bDGeL\%2B5u2IGtjAq08M\%3D. Acesso em: 15.09.2015.

BOUGLÉ-LE ROUX, C. Nuit du Ramadan. Eloge d'une laïcité à géometrie variable. Le Figaro (07.07.2015). Disponível em: http://recherche.lefigaro.fr/recherche/access/lefigaro_fr.php?archive=BszTm8dCk78a tGCYonbyzjutRlh76T8NbpjIUh1N6GFAt8DGYm6k7q9\%2BrEf\%2FHf\%2Ffu2IGtjAq08M\%3 D . Acesso em 17.07.2015.

BRAUMAN, R. Y a-t-il une hiérachie de la souffrance? In. CRASH - Centre de Réfléxion sur l'Action et les Savoirs Humains, 1995. Disponível em: http://www.msfcrash.org/drive/d92c-rb-1995-y-a-t-il-une-hierarchie-de-la-souffrance-_fr-art-p.4_.pdf. Acesso em: 15.08.2015.

BROUZE, É. Apologie du terrorisme: Dieudonné sera jugé en correctionnelle. Rue89 (14.01.2015). Disponível em: http://rue89.nouvelobs.com/2015/01/14/apologieterrorisme-dieudonne-garde-a-vue-257082. Acesso em 28.08.2015.

CASSIAUX, D. Laïcité et valeurs de la République, une géometrie variable. Mediapart (29.03.2015). Disponível em: http://blogs.mediapart.fr/blog/danielcassiaux/290315/laicite-et-valeurs-de-la-republique-une-geometrie-variable. Acesso em: 10.08.2015.

CHAUMONT, J-M. La concurrence des victimes Génocide, identité, reconnaissance. Paris : Éditions la découverte, 1997. 
EID\&A - Revista Eletrônica de Estudos Integrados em Discurso e Argumentação, llhéus, n. esp. ADARR, mai.2016.

DANBLON, E. L'Homme rhétorique Culture, raison, action. Paris : Les Éditions du Cerf, 2013.

DUCROCQ, C. Nuit du Ramadan: "Pour respecter la laïcité, ne célébrons aucune fête religieuse”. Le Figaro (07.07.2015). Disponível em: http://recherche.lefigaro.fr/recherche/access/lefigaro_fr.php?archive=BszTm8dCk78a tGCYonbyzsZ1Wm1BaC62bpjIUh1N6GFAt8DGYm6k7vxDaXUkhvd\%2Bu2IGtjAq08M\%3D . Acesso em 17.07.2015.

EGGS, E. L'argument par l'exemple, l'exemplum et l'appropriation du passé. À propos des 'Justes' de France. In. DANBLON, E. ; FERRY, V. ; NICOLAS, L.; SANS, B. (éds.) Rhétoriques de l'exemple Fonctions et pratiques. Besançon: Presses Universitaires de Franche-Comté, p. 133-151, 2014.

ENGO, J.D. Charlie Coulibaly: l'odieux jeu de mots d'un multirécidiviste? Mediapart (12.01.2015). Disponível em: http://blogs.mediapart.fr/blog/joel-didierengo/120115/charlie-coulibaly-lodieux-jeu-de-mots-dun-multirecidiviste. Acesso em: 18.09.2015.

FAURE, S. La liberté d'expression sous pression. Libération (14/1/2015). Disponível em: http://www.liberation.fr/societe/2015/01/14/la-liberte-d-expression-sous-

pression_1180858. Acesso em: 17.07.2015.

FIALA, P. (éd.), In/égalité/s usages lexicaux et variations discursives $\left(18^{\mathrm{e}}-20^{\mathrm{e}}\right.$ siècles), Paris : L'Harmattan, 1999.

FULDA, A. Indignations sélectives. Le Figaro (9.03.2010). Disponível em: http://premium.lefigaro.fr/editos/2010/03/10/01031-20100310ARTFIG00052-

indignations-selectives-.php. Acesso em: 15.11.2015.

GLUCKSMANN, A. Choc des civilisations? Non: des philosophes. Le Monde (03.03.2006). Disponível em: http://www.lemonde.fr/idees/article/2006/03/03/chocdes-civilisations-non-des-philosophies-par-andre-glucksmann_747283_3232.html.

Acesso em 15.07.2015.

GROSSER, A. Comparer Auschwitz. La Croix (25.01.1995). Disponível em: http://www.la-croix.com/\# Acesso em: 19.11.2015.

HENRY, P. Asile: en Europe, c'est deux poids deux mesures». Rue89 (09/09/2008). Disponível em: http://rue89.nouvelobs.com/2008/09/09/asile-en-europe-cest-deuxpoids-deux-mesures. Acesso em: 05.09.2015.

Ina.fr (10.04.2015). Islam et amalgame. Disponível em: http://www.ina.fr/contenuseditoriaux/articles-editoriaux/islam-et-amalgame. Acesso em 15.09.2015. 
EID\&A - Revista Eletrônica de Estudos Integrados em Discurso e Argumentação, Ilhéus, n. esp. ADARR, mai.2016.

JOFFRIN, L. Pour répondre à BHL. Libération (7.06.2010). Disponível em: http://www.liberation.fr/planete/2010/06/07/pour-repondre-a-bhl_657128. Acesso em: 15.07.2015.

- Précédent. Libération (06.07.2015). Disponível em: http://www.liberation.fr/planete/2015/07/06/precedent_1344602. Acesso em 07.07.2015.

KOREN, R. Quand informer, c'est dire le blanc et le noir : quelques effets pervers de l'oscillation binaire. In. BOGAARD, Paul; ROORYCK, Johan; SMITH, Paul J. (éds.). Quitte ou Double Sens. Articles sur l'ambiguïté offerts à Ronald Landheer. Amsterdam: Rodopi, p. 177-200, 2001.

. Contribution à l'étude des enjeux de la rhétorique laconique : le cas des indications chiffrées. Topique, 83/2, "Représentations du terrorisme », p. 111-124, 2003.

. Argumentation, enjeux et pratique de l' 'engagement neutre': le cas de l'écriture de presse. Semen 17, «Argumentation et prise de position. Pratiques discursives», p. 19-40, 2004.

. De la rationalité et/ou de l'irrationalité des polémiqueurs: Certitudes et incertitudes. Semen [En ligne], v.31, 2011. Disponível em http://semen.revues.org/9061. Acesso em: 14.07.2015.

. Langage et justification implicite de la violence : le cas de l' 'amalgame'. In.

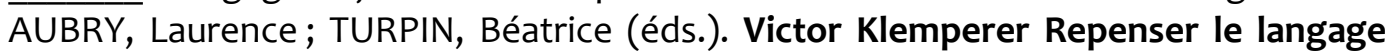
totalitaire. Paris : Presses du CNRS, p. 93-105, 2012.

Le Figaro (9.03.2010). Disponível em: http://premium.lefigaro.fr/editos/2010/03/10/01031-20100310ARTFIG00052indignations-selectives-.php. Acesso em: 15.11.2015.

Le Figaro (06.07.2015). Disponível em: http://recherche.lefigaro.fr/recherche/access/lefigaro_fr.php?archive=BszTm8dCk78a tGCYonbyzjXRdS2HXVSzbpjlUh1N6GHq8BFvLCHrXHfÜ1bDGeL\%2B5u2IGtjAq08M\%3D. Acesso em: 17.07.2015.

Le Figaro (07.07.2015). Disponível em: http://recherche.lefigaro.fr/recherche/access/lefigaro_fr.php?archive=BszTm8dCk78a tGCYonbyzjutRlh76T8NbpjlUh1N6GFAt8DGYm6k7q9\%2BrEf\%2FHf\%2Ffu2IGtjAq08M\%3 D . Acesso em 17.07.2015.

Le Figaro (07.07.2015). Disponível em: http://recherche.lefigaro.fr/recherche/access/lefigaro_fr.php?archive=BszTm8dCk78a tGCYonbyzsZ1Wm1BaC62bpjIUh1N6GFAt8DGYm6k7vxDaXUkhvd\%2Bu2IGtjAq08M\%3D . Acesso em 17.07.2015. 
EID\&A - Revista Eletrônica de Estudos Integrados em Discurso e Argumentação, Ilhéus, n. esp. ADARR, mai.2016.

LEGARET, A. Disproportionné. Le Monde à l'Endroit (27.01.2009). Disponível em: http://alainlegaret.blogspot.co.il/2009/01/par-alain-legaret_27.html. Acesso em: 17.07.2015.

Le Monde (15.06.2015). Disponível em: http://www.lemonde.fr/idees/article/2015/06/15/indispensable-justiceinternationale_4654264_3232.html. Acesso em: 15.09.2015.

Libération (06.07.2015). Disponível em: http://www.liberation.fr/planete/2015/07/06/precedent_1344602. Acesso em 07.07.2015.

MANENTI, B. Une liberté d'expression à deux vitesses? 7 questions pour comprendre. L'OBS Societé (20.01.2015). Disponível em http://tempsreel.nouvelobs.com/charliehebdo/20150120.OBS0346/une-liberte-d-expression-a-deux-vitesses-7-questions-pourcomprendre.html. Acesso em: 15.08.2015.

Mediapart (30.07.2014). Disponível em: http://mediapart.fr/print/437801. Acesso em: 14.07.2015.

M., Stéphane. La Fédération Internationale des Droits de l'Homme dénonce la position de l'UE concernant la bande de Gaza. Mediapart (30/07/2014). Disponível em: http://mediapart.fr/print/437801. Acesso em: 14.07.2015.

PENA-RUIZ, H. Laïcité et égalité, leviers de l'émancipation. Le Monde Diplomatique (02.2014). Disponível em: http://www.mondediplomatique.fr/2004/02/PENA_RUIZ/11036. Acesso em: 05.09.2015.

PERELMAN, C. Le champ de l'argumentation. Bruxelles: Presses Universitaires de Bruxelles, 1970.

- L'empire rhétorique Rhétorique et argumentation. Paris: Librairie philosophique J. Vrin, 1977.

; OLBRECHTS-TYTECA, L. Traité de l'argumentation: La nouvelle rhétorique. 4è édition. Bruxelles, Éditions de l'université de Bruxelles, 1983.

. Rhétoriques, Bruxelles : Éditions de l'université de Bruxelles, 1989.

. Éthique et Droit. Bruxelles : Éditions de l’Université de Bruxelles, 1990.

PERROTIN, D. Explosion des actes islamophobes. Et derrière, quelles condamnations?. Rue89 (24.01.2015). Disponível em: http://rue89.nouvelobs.com/2015/01/24/explosion-actes-islamophobes-derrierequelles-condamnations-257269. Acesso em: 15.08.2015.

RICOEUR, P. Le Juste. Paris : Éditions Esprit, 1995. 
EID\&A - Revista Eletrônica de Estudos Integrados em Discurso e Argumentação, Ilhéus, n. esp. ADARR, mai.2016.

SCHNEIDERMANN, D. Débarquement: recadrages mémoriels. La Gazette d'arrêt sur images (06.06.2014). Disponível em: http://www.arretsurimages.net/breves/2014-0606/Debarquement-recadrages-memoriels-id17537. Acesso em: 10.09.2015.

SCHIFFER, D. S. La dictature au Maroc: silence, on censure, emprisonne, torture et tue. Mediapart (10.02.2012). Disponível em: https://blogs.mediapart.fr/danielsalvatore-schiffer/blog/100212/la-dictature-au-maroc-silence-censure-emprisonnetorture. Acesso em: 15.08.2015.

STEVENS, B. Une manipulation fantasmée. Libération (05.09.2006). Disponível em: www.liberation.fr/tribune/010159361-une-manipulation-fantasmee. Acesso em: 15.08.2015.

20Minutes (4.08.2014). Disponível em: http://www.2ominutes.fr/monde/142513920140804-bordure-protectrice-10-chiffres-resument-dernier-conflit-israelo-palestinien. Acesso em: 27.08.2015.

Como citar :

KOREN, Roselyne. "Dois pesos, duas medidas": justiça, imparcialidade e equidade na mídia francesa contemporânea. Trad. Bruna Toso e Emília Mendes. EID\&A - Revista Eletrônica de Estudos Integrados em Discurso e Argumentação, Ilhéus, n. esp. ADARR, p. 47-74, mai.2016. 